\title{
Menentukan Ketebalan Lapisan Lapuk Berdasarkan Data Geolistrik Resistivitas
}

\author{
Rahmania $^{1 *}$, F D Sastrawan ${ }^{2}$, M Arisalwadi ${ }^{3}$ \\ ${ }^{1,2,3}$ Program Studi Fisika, Institut Teknologi Kalimantan, Balikpapan, Indonesia \\ *E-mail:rahmania19@lecturer.itk.ac.id
}

\begin{abstract}
In building construction planning, roads, or other infrastructures, Soil capacity for placing foundation is an substantial part that must be considered. When the land as construction supporting experiences fracture or shift, then it can generate building failure. The potential for fracturing and soil displacement can be identified from the thickness of weathered layer. Geoelectric resistivity methods of dipole-dipole array were applied in this study to determine the thickness of the weathered layer. The study was conducted at three different measurement locations oriented to east-west. The result of data processing usingRes2dinv software with an inversion technique is $2 D$ resistivity section that represents a conceptual subsurface geological model. From these results, three types of rock layers are identified. The first layer is a weathered layer in the form of topsoil, clay, and sand with resistivity value of 8-276 $\Omega \mathrm{m}$ and the thickness varied from $5 \mathrm{~m}$ to $17 \mathrm{~m}$, the second layer is clay sand with resistivity value of 276$2000 \Omega m$ identified in about $12 \mathrm{~m}$ to infinite depth, and the resistivity values up to $2000 \Omega \mathrm{m}$ the third layer identified at location SS_01 is considered to be coal.
\end{abstract}

Keywords: resistivity, geoelectric, dipole-dipole, weathered layer

\begin{abstract}
Abstrak
Dalam hal perencanaan pembangunan gedung, jalan, maupun infrastruktur lainnya, kestabilan tanah menjadi salah satu bagian penting yang harus diperhatikan. Jika tanah sebagai pendukung bangunan mengalami deformasi berupa rekahan, penurunan atau pergeseran, maka hal tersebut dapat memicu kerusakan konstruksi bangunan. Potensi rekahan,penurunan dan pergeseran tanah dapat diketahui dari ketebalan lapisan lapuk. Metode Geolistrik resistivitas konfigurasi dipol-dipol diaplikasikan dalam penelitian ini untuk menentukan ketebalan lapisan lapuk. Penelitian dilakukan di tiga lokasi pengukuran berbeda dan beroentasi timur-barat. Hasil pengolahan data menggunakan software Res2dinvdengan teknik inversi berupa penampang resistivitas 2D yang merepresentasikan model geologi konseptual bawah permukaan. Dari Hasil tersebut teridentifikasi tiga jenis lapisan batuan. Lapisan pertama merupakan lapisan lapuk yang terdiri dari top soil,lempung dan pasir halusmemiliki nilai resistivitas 8-276 $\Omega \mathrm{m}$ dan ketebalan yang bervariasi dari $5 \mathrm{~m}$ hingga $17 \mathrm{~m}$. Lapisan kedua adalah pasir lempung memiliki nilai resistivitas 276-2000 $\Omega \mathrm{m}$ danteridentifikasi pada kedalaman $12 \mathrm{~m}$ sampai tak hingga, dan lapisan ketiga dengan nilai resistivitas lebih dari $2000 \Omega \mathrm{m}$ yangteridentifikasi pada lokasi pengukuran SS_01 diduga sebagai batu bara.
\end{abstract}

Kata Kunci: resistivitas, geolistrik, dipole-dipole, lapisan lapuk

\section{Pendahuluan}

Pembagunan gedung, jalan, atau infrastruktur lainnya di Institut Teknologi Kalimantan (ITK) saat ini sangat dibutuhkan untuk memenuhi kebutuhan sarana dan prasarana perkuliahan. Proses perencanaan pembangunanharus dilakukan secara cermat dan tepat agar menghasilkan bagunan yang kuat dan kokoh. Tiga foktor penting yang dapat mempengaruhi kekuatan dan kekokohan bangunan adalah jenis struktur bagunan, material yang digunakan, dan kekuatan pondasi [1].

Kekuatan dan kekokohan pondasi sangat bergantung pada kondisi geologi daerah pembangunan. Kondisi geologi yang 
mempengaruhi kekuatan pondasi salah satunya adalah stabilitas tanah [2].Ketika tanah sebagai tempat meletakkan atau menancapkan pondasi mengalami deformasi berupa rekahan, penurunan, atau pergeseran, maka konstruksi bangunan yang ada diatasnya dapat mengalami kerusakan.

Potensi kerusakan bangunan akibat deformasi tanah bawah permukaan dapat diidentifikasi dari ketebalan lapisan lapuk (weathered layer) $[3,4]$. Untuk meminimalisir resiko kerusakan konstruksi ketika dilakukan pembangunan, maka studi bawah permukaan untuk mengidentifikasi ketebalan lapisan lapuk perlu dilakukan. Dewasa ini metode geofisika dan metode geoteknik memiliki keterkaitan yang sangat besar dalam hal pembangunan sarana dan prasarana umum [5]. Salah satu metode geofisika yang banyak digunakan dalam survey bawah permukaan adalah metode geolistrik.

Metode geolistrik memanfaatkan sifat kelistrikan batuan untuk mengetahui kondisi bawah permukaan. Sifat kelistrikan yang digunakan dalam survei geolistrik adalah resistivitas [6]. Nilai resisitivitas batuan diperoleh melalui perhitungan menggunakan parameter arus yang dialirkan kebawah permukaan, nilai parameter bedapotensial yang ditimbulkan oleh penjalaran arus listrik, dan nilai faktor geometri konfigurasi elektroda yang digunakan. Metode geolistrik memilikibeberapa jenis susunan konfigurasi elektroda. Konfigurasi elektroda yang digunakan dalam penelitian ini adalah konfigurasi dipole-dipole yang menghasilkan penampang resistivitas dua dimensi (2D) bawah permukaan.

Penampang resisitivitas 2D bawah permukaan akan memberikan informasi kontras nilai resistivitas batuan dibawah permukaan [7]. Informasi tersebut dikaitkan dengan kondisi geologi lokal dareah penelitian sehingga dapat diinterpretasikan dalam model 2D geologi konseptual bawah permukaan.

Metode geolistrik 2D dengan konfigurasi dipole-dipole dianggap sesuai untuk kajian lapisan lapuk di daerah penelitian karena dapat memberikan gambaran bawah permukaan baik secara lateral maupun vertikal dengan resolusi yang lebih baik sehingga mampu mendeteksi perbedaan struktur batuan yang lebih dalam $[8,9,10]$. Hasil penelitian yang diperoleh merupakan salah satu informasi yang dibutuhkan dalam perencanaan pembangunan di area kampus ITK.

\subsection{Kondis Daerah Penelitian}

Mengacu pada Laporan Status Lingkungan Hidup Kota Balikpapan Tahun 2015, Wilayah Kota Balikpapan sekitar 80\% tersusun oleh jenis tanah ponsolik merah kuning dan pasir halus dengan daya kohesif yang rendah, mudah tererosi dan jenuh air. Tanah Podsolik merah merupakan hasil pelapukan batuan induk yang berumur muda. Mencakup 5\% tanah alluvial yang terbentuk di lingkungan sungai dan pantai yang berkomposisi pasir, lempung, lumpur dan sekitar $15 \%$ luas wilayahnya ditempati oleh tanah pasir yang mengandung kuarsa, lempung, serpih dengan sisipan napal dan batubara [11].

Kondisi Geologi Wilayah Kota Balikpapan Secara Geomorfologi adalah sekitar $85 \%$ luas Wilayah merupakan daerah yang berbukti-bukit dan hanya sekitar $15 \%$ dari keseluruhan wilayah termasuk daerah datar yang menempati daerah sepanjang pesisir pantai. Jika ditinjau dari stratigrafi, jenis formasi batuan yang tersingkap di daerah Balikpapan dari tua kemuda adalah Formasi Balikpapan, Formasi Kampung Baru, dan endapan Alluvial [12].

Berdasarkan pada peta geologi lembar Balikpapan tahun 1994 dari Puslitbang Geologi, daerah penelitian yaitu area hutan kampus ITK merupakan Formasi Kampung Baru yang tersusun atas batu pasir kuarsa dengan sisipan batu lempung, serpih, batu lanau, dan sisipan batubara [13]. 


\subsection{Metode Geolistrik Tahanan Jenis}

Metode geolistrik merupakan salah satu metode geofisika yang dapat digunakan untuk menyelidiki kondisi bawah permukaan dengan menggunakan sifat-sifat kelistrikan batuan, yaitu resistivitas atau tahanan jenis, konduktivitas, dan lainnya. Dalam eksplorasi geolistrik, pengukuran resistivitas dilapangan diturunkan dari asumsi bahwa resistivitas bumi adalah homogen setengah tak berhingga. Pada kenyataannya, sifat bumi adalah umumnya berlapis (terutama di dekat permukaan) sehingga asumsi bahwa medium bumi homogen tidak terpenuhi [14]. Dengan demikian, nilai resistivitas disebut resistivitas semu $\left(\rho_{a}\right)$ dan dinyatakan dalam persamaan:

$$
\rho_{a}=\frac{V}{I} \kappa
$$

Iadalah variabel besar arus yang dialirkan ke bawah prmukaan, $V$ merepresentasikan beda potensial akibat arus, dan faktor geometri $\kappa$ besarnya ditentukan dari susunan elektroda arus [15].

Penyelidikan bawah permukaan untuk mengetahui ketebalan lapisan lapuk pada penelitian ini dilakukan dengan menggunakan metode geolistrik konfigurasi dipole-dipole. Gambar 1 Menunjukan jarak antara elektroda arus ( $\mathrm{C} 1$ dan $\mathrm{C} 2)$ dan elektroda potensial (P1 dan P2) adalah $a$, sedangkan elektroda arus dan elektroda potensial terpisah sejauh na. Notasi $n(n=1,2,3, \ldots \ldots . n)$ adalah faktor kali pemindahan elektroda potensial. Semakin besar nilai $n$, maka kedalaman penyelidikan semakin besar. Faktor geometri untuk konfigurasi dipole-dipole dituliskan dalam persamaan berikut:

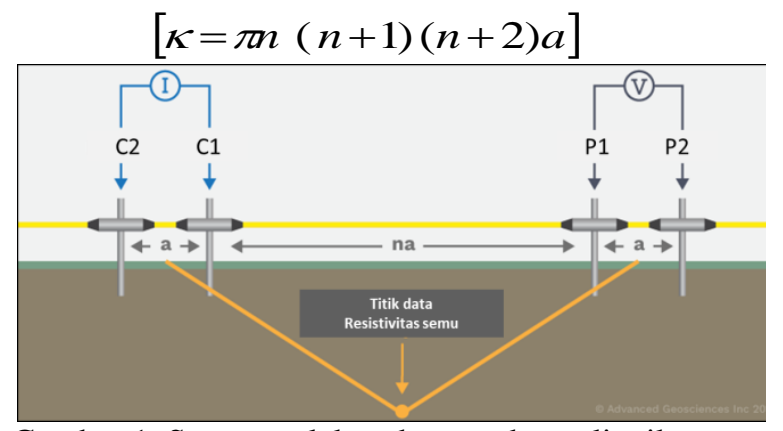

Gambar 1. Susunan elektroda metode geolistrik konfigurasi dipole-dipole [16].

\section{Metode Penelitian}

Aplikasi metode geolistrik konfigurasi dipole-dipole untuk studi ketebalan lapisan lapuk dilakukan di areahutan kampus ITK yang akan digunakan sebagai lahan pembangunan gedung, jalan, atau pun infrastruktur baru lainnya di masa yang akan datang.

Secara administrasi ITK terletak di Kelurahan Karang Joang, Kecamatan Balikpapan Utara, Kota Balikpapan, Provinsi Kalimantan Timur (Gambar 2).

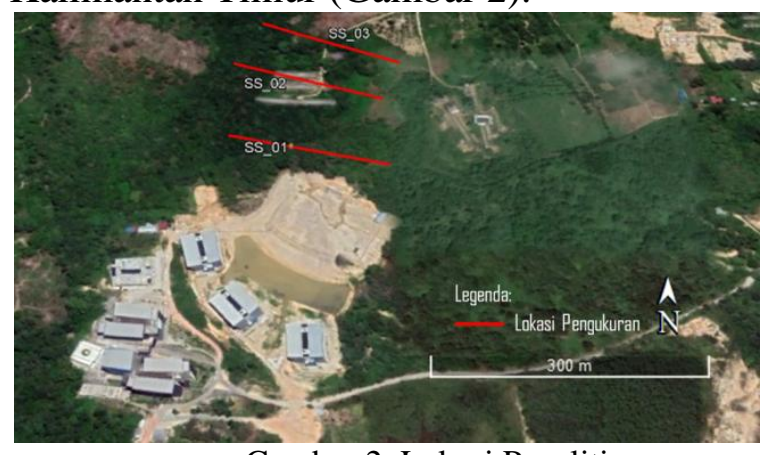

Gambar 2. Lokasi Penelitian

Pengukuran dilakukan di tiga (3) lokasi berbeda dengan panjang bentangan masingmasing $200 \mathrm{~m}$, dan spasi antara dua elektroda arus dan dua elektroda potensial adalah $20 \mathrm{~m}$. Metode geolistrikresistivitas dilakukan dengan cara menginjeksikan arus ke dalam tanah menggunakan dua elektroda arus, kemudian beda potensial diukur dengan dua elektroda lain yang terhubung dengan alat geolistrik Naniura. Parameter fisika yang didapat dari pengukuran di lapangan adalah nilai arus ( $I)$, beda potensial $(V)$. Nilai resistivitas $\operatorname{semu}\left(\rho_{a}\right)$ dihitung dari rasio antara nilai bedapotensail terhadap arus listrik dikalikan dengan faktor geometrikuntuk konfigurasi dipole-dipole.

Nilai resistivitas semu hasil perhitungan kemudian diolah menggunakan software Res2Dinv dengan teknik pemodelan leastsquare inversion yang merupakan program bawaan dari software. Untuk mengoptimalkan hasil yang diperoleh, maka program diatur untuk merubah spasi elektorda yang semula $20 \mathrm{~m}$ menjadi $10 \mathrm{~m}$. Proses inversi akan mengubah resistivitas semu menjadi resistivitas sebenarnya 
sehinggadiperoleh penampang resistivitas perkedalaman yang mengambarkan kondisi bawah permukaan, termasuk ketebalan lapisan lapuk (weathered layer) dan kedalaman batuan kerasa berdasarkan kontras nilai resistivitas.

\section{Hasil Penelitian}

\subsection{Lokasi Pengukuran SS_01}

Hasil pemodan resistivitas 2D bawah permukaan pada lokasi pengukuran SS_01 teridentifikasi tiga lapisan berbeda yang digambarkan dalam skala warna [Gambar 3]. Lapisan pertama yang didominasi warna biru tua hingga hijau memiliki nilai resistivitas 8$276 \Omega \mathrm{m}$ dengan ketebalan 5-17m.

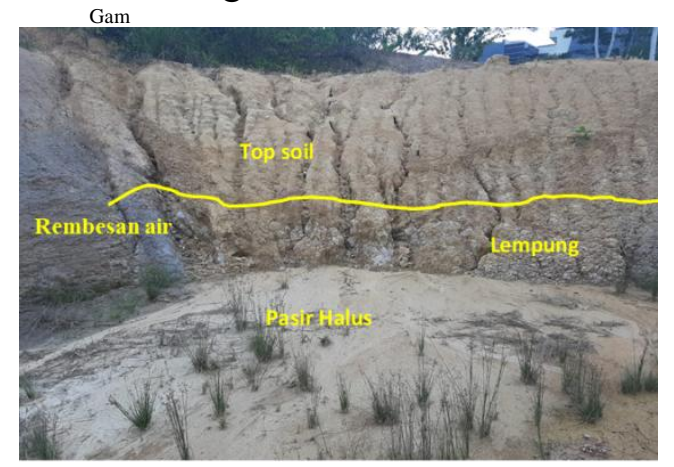

Gambar 4. Singkapan yang ditemukan disekitar lokasi penelitian.

Berdasarkan hasil pengamatan di sekitar lokasi pengukuran (Gambar 4), singkapan tanah permukaan didominasi oleh tanah podsolik berwarna merah-kuning, lempung dan pasir halus, serta ditemukan beberapa rembesen air sehingga dapat simpulkan bahwa nilai resistivitas rendah dilapisan pertama diinterpretasi sebagai lapisan lapuk yang terdiri dari top soil, lempung, dan pasir halus,

sedangka nilai resistivitas lebih tinggi dipermukaan yang ditunjukkan dengan warna kuning hingga merah diperkirakan karena adanya perbedaan kadar air dan komposisi lempung di lapisan tersebut. Lapisan kedua yang disimbolkan dengan warna kuning hingga merah memiliki nilai resistivitas 276$2000 \Omega \mathrm{m}$ diiterpretasi sebagai pasir lempung. Nilai resistivitas tinggi yang teridentifikasi pada lapisan ketiga di eletroda yang berjarak
$80 \mathrm{~m}$ hingga $120 \mathrm{~m}$ dan berada pada kedalam $28 \mathrm{~m}$ dari permukaan diinterpretasi sebagai batu bara.

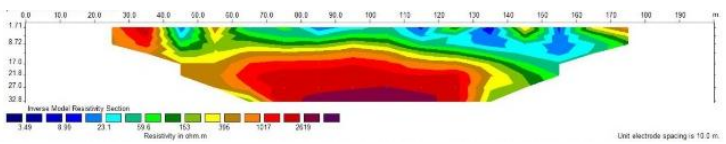

Gambar 4. Model penampang 2D resistivitas bawah permukaan lokasi pengukuran SS_01.

\subsection{Lokasi Pengukuran SS_02}

Model 2D resistivtas bawah permukaan pada lokasi pengukuran SS_02 menunjukkan ada kontras nilai resistivitas antar lapisan sehingga dapat teridentifikasi 2 lapisan berbeda dengan jangkauan kedalaman hingga 32,8 $\mathrm{m}$ dari permukaan (Gambar 5)

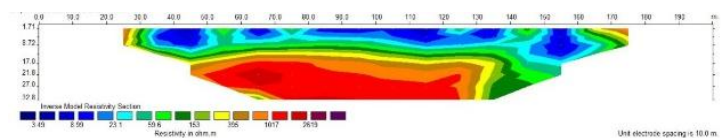

Gambar 5. Model penampang 2D resistivitas bawah permukaan lokasi pengukuran SS_02.

Nilai resistivitas 8-276 $\Omega \mathrm{m}$ ditunjukkan dengan warna biru tua hingga hijauyang mendominasi lapisan permukaan dengan ketebalan yang bervariasi dari $8 \mathrm{~m}$ hingga 17 $\mathrm{m}$ diiterpretasi lapisan lapuk yang terdiri dari top soil, lempung, dan pasir hasul. Lapisan kedua yang ditunjukkan dengan warna kuning hingga merah denganrentang nilai resistivitas 276-2000 $\Omega \mathrm{m}$ diinterpretasi sebagai pasir lempungan, sedangkan nilai resistivitas yang lebih rendah yang ditunjukkan dengan warna hijau diperkirakan karena perbedaan kadar air dan komposisi lempung pada lapisan tersebut.

\subsection{Lokasi Pengukuran SS_03}

Hasil pengukuran metode resistivitas 2D konfigurasi dipol-dipol pada lokasi pengukuran SS_03 terlihat memiliki pola kemiripan dengan hasil pemodelan resistivitas bawah permukaan pada lokasi pengukuran SS_02 (Gambar 6). Lapisan pertama yang ditunjukkan dengan warna biru tua hingga 
hijau memiliki nilai resistivitas 8-276 $\Omega \mathrm{m}$ dan relatif rendah jika dibandingkan dengan lapisan lain di bawahnya.

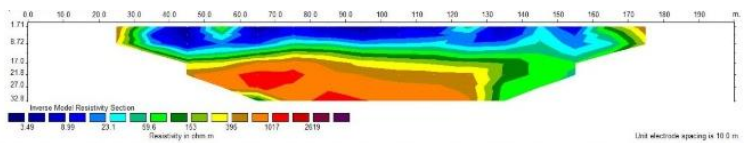

Gambar 6 Model penampang 2D resistivitas bawah permukaan lokasi pengukuran SS_01.

Nilai resistivitas rendah pada lapisan pertama diinterpretasi sebagai top soil, lempung dan pasir halus dengan ketebalan sekitar 12 meter di sepanjangan lintasan pengukuran. Lapisan kedua yang ditunjukkan dengan warna kuning hingga merah dengan nilai resistivitas $<2000 \Omega \mathrm{m}$ diidentifikasi sebagai lapisan pasir lempung, sedangkan nilai resistivitas yang lebih rendah yang ditunjukkan dengan warna hijau diperkirakan karena perbedaan kadar air dan lempung pada lapisan tersebut.

Hasil penelitian dalam bentuk model penampang resistivitas $2 \mathrm{D}$ bawah permukaan dari ketiga lokasi pengukuran, yaitu SS_01, SS_02, dan SS_03 terlihat memiliki pola yang sama. Ketiganya menunjukkan ada kontras nilai resistivitas yang cukup besar antara lapisan permukaan dengan lapisan lain di bawahnya. Nilai resistivitas rendah di permukaanmerupakan lapisan lapuk (weatherd layer)yang terdiri dari top soil, lempung dan pasir halus, sedangkan nilai resistivitas yang cukup tinggi pada lapisan bawah diperkirakan sebagai batu pasir lempungan dan batu bara yang teridentifikasi hanya pada lintasan pengukuran SS_01.Keberadaan batu barayang bersifat setempat (spot) sesui dengan informasi geologi pada peta geologi lembar Balikpapan dan beberapa singkapan yang ditemukan disekitar lokasi penelitian.

Informasi geologi bawah permukaan, mencakup ketebalan lapisan lapuk dan kedalaman batuan kerasdapat dijadikan sebagai data dukung dalam merencanakan pembangunan agar potensi kegagalan konstruksi akibat rekahan, penurunan, atau pergesran tanah bawah permukaan dapat diminimalisir. Keberadaan lapisan lapuk yang tebal dan berkomposisi lempung menjadi kurang menguntungkan pada suatu konstruksi karena lempung memiliki tingkat kestabilan yang rendah ketika mengalami pembebanan $[17,18]$. Untuk memperoleh konstruksi yang kuat dan kokoh perlu rekayasa geoteknik seperti perbaikan kondisi tanah, atau memasang pondasi hingga ke batuan keras dibawah permukaan[19].

\section{Kesimpulan}

Berdasarkan hasil penelitian yang diperoleh dalam bentuk penampang resistivitas 2D dari ketiga lintasan pengukuran diketahui susunan lapisan bawah permukaan daerah penelitian, terdiri dari lapisan lapuk dengan rentang nilai resistivitas 8-276 $\Omega \mathrm{m}$, lapisan pasir lempung dengan nilai resistivitas 276-2000 $\Omega \mathrm{m}$, dan batu bara yang teridentifikasi pada lintasan SS_01. Lapisan lapuk yang terdiri dari top soil, lempung, dan pasir halus memiliki ketebalan yang bervariasidari 5-17 $\mathrm{m}$ di bawah permukaan.

\section{Saran}

Identifikasi ketebalan lapisan lapuk dapat dilakukan dengan pendekatan lainseperti metode refraksi dan data bor untuk memperoleh hasil yang lebih koprehensif. Selain itu pendekatan geokimia juga dapat dilakukan untuk mengetahui karakteristik lempung di lokasi penelitian.

\section{Ucapan Terimakasih}

Ucapan terimakasih disampaikan kepada Ditjen Penguatan Riset dan Pengembangan Kementerian Riset, Teknologi, dan Pendidikan Tinggi melalui LPPM ITK yang telah mendanai kegiatan penelitian ini sehingga dapat terlaksana dengan baik.

\section{Daftar Pustaka}

[1]M.W. Nugroho, F.A.N. Farida A, dan K. Maya, Analisis Struktur Lapisan Bawah Permukaan Dengan MetodeGeolistrik Dalam Perencanaan Pondasi, Jurnal CIVILLa, Vol. 3, No. 2, pp.168-191, 2018. 
[2]A.A., Alfaiz , J. Hutahaean, Penentuan Lapisan Keras Untuk Kelayakan Pembangunan Gedung Bertingkat Menggunakan Metode Geolistrik Resistivitas Di Pesisir Pantai Kahona Kabupaten Tapanuli Tengah , Jurnal Einstein Vol.5, No.3, pp.1-7, 2017.

[3]V.Y. Artono, R. Efendi, dan Sandra, Identifikasi Lapisan Lapuk Bawah Permukaan Menggunakan SeismikRefraksi di Desa Lengkeka Kecamatan Lore Barat Kabupaten Poso, Journal of Science and Technology, Vol.6, No.3.hal. 291-300, 2017.

[4]H. Sulistiawan, I. Yulianti, dan S.Adi, "Identifikasi Studi Ketebalan Lapisan Sedimen Daerah Kampus Unnes dengan Menggunakan Metode Mikroseismik,"Prosiding Sng 2016, 2016, pp. 42-47.

[5]H. Suntoko, dan L.T. Mauritz, "Penyelidikan Geoteknik untuk Pondasi Dangkal di Calon Tapak Pembangkit Listrik Tenaga Nuklir (PLTN) Daerah Ujung Lemahabang,"Prosiding seminar nasional ke12 Teknologi dan Keselamatan PLTN SertaFasilitas Nuklir. Yogyakarta 2006, 2006, pp.12-13.

[6]F.D.Sastrawan, dan J.A.Latifan, "Estimasi kedalamn akuifer dangkal daerah TPA manggar dengan menggunakan metode geolistrik konfigurasi wenner", Jurnal Sains Terapan, Vol.5, No.2 pp.131-136, 2019.

[7] B. Nurdiyanto, I. Suyanto , B. Sunardi, dan P. Susilanto, Tomografi Geolistrik Untuk Identifikasi Litologi Pada Lokasi Rencana Bendung Dan Terowongan Di Sulawesi Utara, Jurnal Meteorologi Dan Geofisika, Vol. 17 No. 1, pp. 15-23,2016.

[8] J.M. Reynolds, J.M. An Introduction toApplied andEnvironmental Geophysics. NewYork: Jhon Geophysicsin Hidrogeological andWiley and Sons Ltd.

[9] GF Instruments. 2007. Short Guide for Resistivity Imaging. Jecna: Geophysical Equipment and Services.

[10] Sari, W.P., Akman, dan Hidayati. 2018, "Analisis Struktur Berdasarkan Data Geolistrik Tahanan Jenis Konfigurasi Schlumberger dan Konfigurasi Dipole-Dipole. Di Kecamatan Malalak Kabupaten Agam "Pillar of Physics, Vol. 11 No. 2, pp. 25-32, 2018.

[11]Pemerintah Kota Balikpapan Badang Lingkungan Hidup, Buku Laporan Status
Lingkungan Hidup Kota Balikpapan. Balikapapan, 2015.

[12] B. Nurdiyanto, I. Suyanto , B. Sunardi , dan P. Susilanto, Tinjauan Geologi Terhadap Potensi dan Tingkat Kerawanan Bahaya Longsor di Kota Balipapan-Kalimantar Timur, Jurnal Teknologi, Vol. II, Edisi 14, pp. 9-29, 2009.

[13] S.Hidayat, I. Umar, dan Badang Geologi, Peta Geologi Lembar Balikpapan Kalimantan.Bandung: Pusat Penelitian dan Pengembangan Geologi, 1994.

[14]M.E. Everret .Near-Surface Applied

Geophysics, New York, Cambridge University Press, 2013.

[15] W.M. Telford, L.P. Geldart, dan R.E. Sheriff. Applied Geophysics, 2nd edition.Cambridge:Cambridge University Press, 1990.

[16] AGI USA, Dipole-Dipole Array: Electrical Resistivity Methods, Part 3, (https://www.agiusa.com/dipole-dipole), diakses 28 Agustus 2020.

[17] M.A. Nusantara,Analisa Daya Dukung Pondasi Dangkal Pada Tanah Lempung Menggunakan Perkuatan Anyaman Bambu Dan Grid Bambu Dengan Bantuan Program, Jurnal Teknik Sipil dan Lingkungan, Vol. 2, No. 3, pp. 364-372, 2014.

[18] B.D.Yuspancana, W. Utama, M.S. Purwanto, A. S. Bahri, Integrasi Data Resistivitas 2d Dengan Parameter Fisis Dan Mekanis Tanah Untuk Evaluasi Daya Duku Tanah (Studi Kasus: Ruas Jalan Kawasan Jiipe, Manyar, Gresik),Jurnal Geosaintek, Vol. 5, No. 2, pp. 84-89, 2019.

[19] Syamsurizal, Cari, Darsono, Aplikasi Metode Resistivitas Untuk Identifikasi Litologi Batuan Sebagai Studi Awal Kegiatan Pembangunan Pondasi Gedung. Indonesian Journal of Applied Physics, Vol.3, No.1 pp.99-106, 2013. 